\title{
The Symbolic Characteristics of Square and Circle in Fashion Design
}

\author{
Aili Zhu, Hu Yue \\ School of Fashion Technology, Shanghai University of Engineering Science, Shanghai, China \\ Email: 2540755339@qq.com
}

How to cite this paper: Zhu, A. L., \& Yue, H. (2018). The Symbolic Characteristics of Square and Circle in Fashion Design. Art and Design Review, 6, 43-47.

https://doi.org/10.4236/adr.2018.61004

Received: August 29, 2016

Accepted: August 30, 2016

Published: February 13, 2018

Copyright $\odot 2018$ by authors and Scientific Research Publishing Inc. This work is licensed under the Creative Commons Attribution International License (CC BY 4.0).

http://creativecommons.org/licenses/by/4.0/

\begin{abstract}
This article mainly analyzes the square and circle of the modeling elements used in the Chinese and Western clothing, and illustrates the symbolic meaning of them. From the application of square and circle in ancient Chinese dress, square and circle in the structure of ancient Chinese dress are not just simple graphics display; they are also endowed with profound cultural connotations. However, the pursuit of square and round objective beauty in western traditional dress also has an intuitive meaning. Squares and circles are widely and deeply rooted in modern clothing design expanding their expression of beauty by the designers. At the same time, in this article, the author also makes a description of the application of the square and circle in jewelry works. Expression of the concept of geometrical pattern in the use of fashion design is not only a geometric pattern decoration, but also a symbolic language.
\end{abstract}

\section{Keywords}

Dress, Geometric Pattern, Graphic Language, The Square and Circle

\section{Introduction}

Yang Ming wrote about the geometric elements and clothing design in his article: The application of geometric shape has a long history in apparel modeling and pattern; the three-dimensional structure of geometric patterns in the modern fashion design for color and fabric has a new expression and the significance of the times (Yang \& Sun, 2011). In this article, the author specifically explains the cultural meanings of the circular and square forms of decoration in Chinese and Western clothing. 


\section{The Cultural Connotation of the Square and Circle in the Ancient Chinese Costume}

There is an ancient Chinese philosophy called "The Orbicular Sky and Rectangular Earths", Orbicular sky represents the "Heaven Principles", this concept is harmony and circulation law; rectangular earth reflects integrity and etiquette of the humanity. The true value of the ideology is the "Harmony between man and nature". This oriental philosophy has been widely used in our people's daily life such as Chinese ancient copper coins have a square hole inside a circle, Chinese characters are rounded to square. Architecture goes from the former round houses to the later quadrate courtyard. It also a deep influence on the field of clothing, music, carving and painting, etc.

Square and circle are the most important symbolic emblems in traditional Chinese, they are not just a geometric figure, but they also imply a kind of humanistic spirit, vividly record which are endowed with the cultural connotation of the ceremonial and practical Chinese dress by the Ingenious Conceptualization of the upper rulers and craftsman perfectly combines the visible structure with the underlying culture. Chinese costumes emphasize coordination between Yin and Yang, firmness and flexibility. Figure 1 depicts the different beauty of the square and round beauty of their own and the combination of the square and circle. "Square" is a kind of masculine beauty, reflect a continuous straight lines less detail, composition expansion, bold color contrast and heavy fabric stiff in the clothes; "Circle" is reflected in the feminine side, characteristic of the clothes is beautiful contour curve, soft with details of the discontinuous line, composition compact, elegant color contrast is not obvious, the fabric is soft and light (Zhang, 2009).

Artificiality imitated nature in ancient China. On the Confucian views, the round sleeved corresponds to "spherical heavens" and square neck symbolized "square earth" of deep clothing that was worship of ancient Chinese to heaven. The ancients concealed the heaven and earth under the coat to remind themselves can't take the law into one's hands; the crown was composed of circular cap body and round front and square rear of quadrate plate with small top and big bottom, which was one form of traditional Chinese hat, this indicated "Heaven and Earth" (Huang \& Chen, 2014).

\section{Quadrate and Circular Structures Reflected in Western Garments}

Instead of implicit expression, the occidental culture prefers the direct expression.
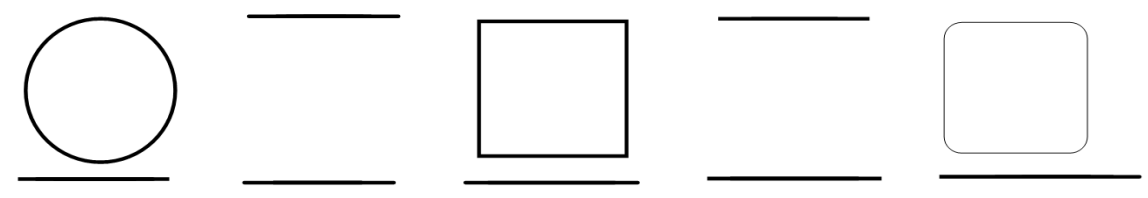

Figure 1. Square/circle and the combination of them. 
They pay attention to visual effects and emphasize on the objective beautymodelling, line, pattern and color in fashion design, Due to the curve making a circle is more changeable than straight line, the round is symmetry, plumpness and fluency, which gives people satisfactory and substantial emotional experience (Zhao, 2012). Different from round, square has flat, steady and normative characteristic, it consists of two parallel horizontal and vertical lines that constitute two mutually restrictive forces (Wang, 2014).

Ancient Greeks and Romans upheld nature and enjoyed freedom. In their Garments, Doric Chiton and Chiton drawn lessons from the style of the Greek architecture, they were a piece of white rectangular without being cropped fabric that fasten with pins on body for making people's life more convenient ( $\mathrm{Xu}$, 2001). In the 19th century, gentleman was very popular in wearing top hat, one of the top hat had cylindraceous shape in silk. Square and round both connotation from the outside world and attract us, it is not only our life principle, at the same time, the injection specification and theoretical source are designed.

\section{Circle and Square in Modern Fashion Design}

With the change of the times, people's aesthetic standards change greatly. Under the background of a new era, circle and square development of many new forms of expression and performance, and transmit an abundance of the cultural information. Geometric pattern not only beautifies our life, and a kind media of information communicate can transcend the language barriers, ethnic and geographical barriers by static images to communicate with the receivers (Gao, 2010).

It is generally known that "Queen of Dot"-Japanese artist Yayoi Kusama is good at coating object surface with different dot. In 2012, she and LV launched KUSAMA, show window, handbag, shoe and accessories were covered with her iconic dot. She muses on universe, life and disease through dot structural assemblage (Zhang, 2014). Hippie, academic, reminiscent and leisure chequer with high frequency in Modern Clothing Design has been widely used. It originated from the pattern emerged during humankind made textiles. With changing times, plaid innovates new application, one representative of the Scottish Kilt which is used in some school uniforms (Chen, 2009).

\section{To Explore Circle and Square in Practice}

Figure 2 is jewelry which the author utilizes jewelry design methods on color contrast, size contrast, shape contrast, her inspiration from natural tree. This works uses rectangular ebony, silver and brassiness as raw material. Ebony is hollowed out several various sizes in circular leaf, irregular rectangular trunk and linear branch and puts them together into a geometry of tree. Silver and brassiness are made different balls by firing at high temperature, and then adorns tree, great circles are among some small rounds breaks dull, thick solid atmosphere have the effect of all the stars bend towards the moon, that add 


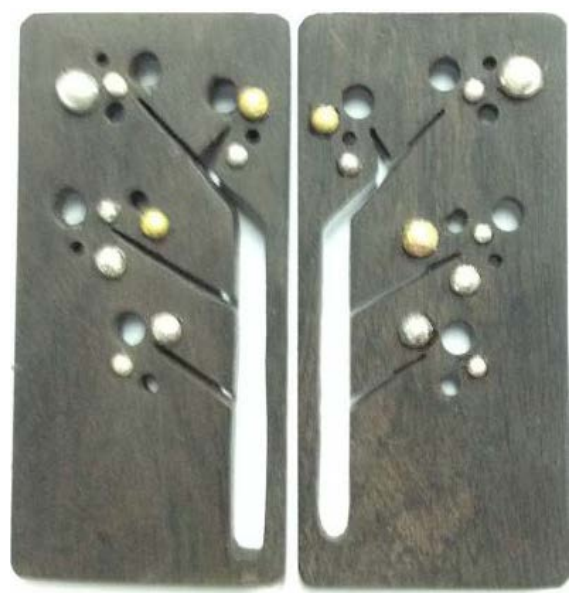

Figure 2. Pendant.

three-dimensional and layering effect to this handicraft. For avoiding the depressing feeling, the designer adopts many methods cause the jewelry to be lively and vivid. On part, seemingly disparate permutation contain certain rules. The chiaroscuro caused by yellow brass, white silver and ebony. Rectangle contrasts with round in shape. Fresh and natural visual effect of the works appeal to the tidal current of "Return to nature" (Qian, 2016).

\section{Conclusion}

Application of round and square on dress has a long history. They are both simple geometric forms and graphic languages. With the development of the society, more and more fashion designers devote to exploring the geometrical forms that display diversified forms and convey a great deal of information in the dress. Nowadays, clothing design in order to meet the needs of the market, needs to combine with the cultural background and new fabrics and new processes to create a combination of national characteristics and fashion, The designers should absorb the essence of the excellent works of ancient and modern. Square and circle are the principles of our life, and we also do design standards to design more formal language and theoretical sources for design.

\section{References}

Chen, X.-Y. (2009). The Applied Exploration of Lattice in Modern Clothing Industry. Beijing: Beijing Institute of Fashion Technology.

Gao, H.-Y. (2010). Research of Application of Vision Element of Circular in Graphic Design. Hefei: Hefei University of Technology.

Huang, N.-F., \& Chen, J.-J. (2014). History of Chinese Costume. Shanghai: Shanghai People's Publishing House.

Qian, Z.-Y. (2016). An Analysis of Artistic Jewelry Design. Art and Design, 3, 83-85.

Wang, Y.-Y. (2014). Emotional Expression of Simple Geometric Figures. Nanjing: Nanjing Normal University.

Xu, X. (2001). Chinese and Foreign Costume Culture of Female. Beijing: China Textile \& 
Apparel Press.

Yang, M., \& Sun, J. (2011). 3D Representation of Geometric Modeling Arts in Modern Fashion Design. Journal of Nanning Polytechnic, 3, 24-27.

Zhang, D.-Y. (2014). An Analysis of Symbols about Yayoi Kusama's Works. DONGJING WENXUE, 10, 5 .

Zhang, Z.-C. (2009). Chinese Costume Culture (Version 2). Beijing: China Textile \& Apparel Press.

Zhao, L.-S. (2012). Wisdom of the Clothing. Beijing: China Society Press. 